Anuario de Estudios Americanos, 73, 2

Sevilla (España), julio-diciembre, 2016, 657-687

ISSN: 0210-5810. DOI: 10.3989/aeamer.2016.2.11

\title{
Aportes a la historia sísmica de Chile: el caso del gran terremoto de 1730\%/
}

\section{Contributions to the Chile's Seismic History: the Case of the Great Earthquake of 1730}

\author{
María X. Urbina Carrasco, orcid.org/0000-0002-3203-0269, \\ Nicolás Gorigoitía Abbott, orcid.org/0000-0001-9018-2730 \\ y Marco Cisternas Vega, orcid.org/0000-0002-8108-997X \\ Pontificia Universidad Católica de Valparaíso
}

De acuerdo a nuevos y antiguos documentos se concluye que el terremoto de 1730 en Chile estuvo compuesto por dos sismos independientes, cada uno con un tsunami asociado. Considerando la extensión latitudinal de los daños y el tamaño de los tsunamis, este puede ser calificado como el mayor evento sísmico ocurrido en la historia de Chile metropolitano o central. Estas conclusiones permiten conocer mejor la secuencia sísmica del centro de Chile, la historia sísmica del país, y contribuye al conocimiento de la historia colonial del reino de Chile.

Palabras Clave: Historia sísmica; Terremoto y Ttsunami de 1730; Chile.

According to the new and previously known documents it is concluded the earthquake of Chile in 1730 was composed by two independent earthquakes, each associated to a tsunami. Considering the latitudinal extension of the damage and the size of the tsunamis, it can be taken as the largest seismic event occurred in the history of Metropolitan or Central Chile. These conclusions allow to know better the seismic sequence of Central Chile, the Seismic History of the country, and contribute to the knowledge of the colonial history of the kingdom of Chile.

KEYWORDS: Earthquake history; 1730 Earthquake and Tsunami; Chile.

Copyright: () 2016 CSIC. Este es un artículo de acceso abierto distribuido bajo los términos de una licencia de uso y distribución Creative Commons Attribution (CC-by) España 3.0.

* Proyectos FONDECYT (Fondo Nacional de Desarrollo Científico y Tecnológico, de la Comisión Nacional de Investigación Científica y Tecnológica, Ministerio de Educación, Chile) Regulares, $\mathrm{N}^{\circ}$ 1110848, 2011-2014, «¿Es inmune Chile Central a los terremotos y tsunamis gigantes?», y N. ${ }^{\circ} 1150321,2015-2018$, «Recurrencia de grandes terremotos y tsunamis en Chile Metropolitano». 
Desde fines del siglo XIX la Historia se ha ocupado sistemáticamente de conocer mejor los terremotos, estudiándolos desde varias perspectivas y con distintos objetivos, siendo uno de ellos el aumentar y precisar la información y cronología sísmica por países o regiones. Para el caso de Chile, el más completo catálogo de terremotos fue publicado por Montessus de Ballore, quien compiló y dio a conocer la documentación disponible para estudiar cada terremoto en Chile, hasta el momento en que escribió, 1911. Este registro ha sido complementado más tarde, principalmente por Cinna Lomnitz en 1970 y 2004. ${ }^{1}$ Los países latinoamericanos también se han ocupado de construir su cronología sísmica, destacando en ello Perú, con los trabajos de Giesecke y Silgado de 1981, otro de Silgado y el reciente de Lizardo Seiner, ${ }^{2}$ y México, donde tres investigadores han publicado una completa cronología de los sismos desde la época prehispánica hasta el año $1821 .^{3}$ Además de los catálogos y cronologías, y siempre refiriéndonos a Latinoamérica, existen estudios de caso en que se entregan más antecedentes para conocer mejor uno o más terremotos en particular. ${ }^{4}$

En una categoría distinta se encuentran los estudios de un terremoto o una secuencia de ellos, en un contexto temporal o espacial delimitado, para explicar su papel en procesos económicos, políticos, sociales o culturales. ${ }^{5}$ Dentro de ellos, además, es posible distinguir los estudios que interrelacionan terremotos u otros eventos físicos de gran impacto como huracanes y erupciones volcánicas, con desastres asociados y la acción-reacción de las sociedades que los han experimentado. ${ }^{6}$ Todo esto ha producido tal

1 Montessus de Ballore, 1912-1916. Lomnitz, 1970 y 2004.

2 Giesecke y Silgado, 1981. Silgado, 1985. Seiner, 2009-2012.

3 Rojas, Pérez y García, 1987.

4 En cuanto a Chile, por ejemplo: Palacios, 2012, para los terremotos de Concepción; Ramírez, 1988, sobre el terremoto de 1575; Udías et al., 2012, sobre varios de esos terremotos.

5 Por ejemplo Altez, con una larga trayectoria tanto para la sismicidad histórica de Venezuela, como para la relación entre terremotos y sociedad, de quien citamos, entre otros trabajos, su libro publicado en 2010. Podríamos también destacar, en esta misma relación, entre muchos otros, a Palacios (2014) y la «abogacía telúrica»; a Pérez-Mallaína (2000), con el terremoto de 1687 de Perú y su utilización por las autoridades contemporáneas para lo que llama «fabricación de un mito»; al mismo PérezMallaína, que observó (2001 y 2005) el comportamiento de la sociedad limeña a través del terremoto de 1746; mientras que, para este mismo sismo, Walker (2004 y 2008) ha puesto el acento en cómo las relaciones de poder se alteran y comportan ante estas coyunturas tan críticas. Asimismo, destacamos el primer libro de García y Suárez (1996), que ofrece mucha y muy bien dispuesta información, agrupada en varios índices sobre los terremotos de México hasta el año 1912, refiriendo sus fuentes y bibliografía, y el segundo tomo (2001), que ofrece varios estudios de caso, desde una perspectiva social.

6 Por ejemplo, y siempre para Latinoamérica, destacamos a Margarita Gascón, quien en 2001 y 2005 publicó sus investigaciones (entre múltiples otras) sobre la relación entre historia y desastres naturales, para contribuir a la historia ambiental; a María Eugenia Petit-Breuilh, quien ha estudiado la 
cantidad de libros y artículos que es imposible dar cuenta de ellos aquí, aun cuando nos restrinjamos a los grandes terremotos, como en este caso.

Los sismólogos consideran que un terremoto es grande cuando en la escala de Magnitud de Momento (Mw) —escala basada en la energía total liberada por un sismo- es igual o superior a 8. ${ }^{7}$ En el caso de Chile, este se localiza íntegramente sobre una joven y activa zona de subducción de placas (la de Nazca y la Sudamericana), siendo el país más sísmico del mundo, generando un terremoto grande cada 12 años, en promedio. ${ }^{8}$ En el sur de esta zona de subducción hubo en 1960 un megaterremoto que devastó el territorio entre las penínsulas de Arauco, por el norte, y Taitao, por el sur (37 a 47 grados de latitud sur), y que por su medida $(9,5)$ pasó a la categoría de gigante (igual o mayor de $9 \mathrm{Mw}$ ): fue el terremoto más grande que ha habido en la historia de la humanidad. Los terremotos gigantes son altamente destructivos, incluso en el país mejor preparado del mundo, como quedó demostrado recientemente por el terremoto magnitud Mw 9 en Japón, del año 2011. El terremoto de 1960 desencadenó un tsunami trans-Pacífico que cobró cientos de víctimas en Chile y al otro lado del planeta, en Hawaii y Japón. ${ }^{9}$ La investigación paleosismológica ha obtenido evidencias de haber ocurrido ocho eventos similares, en la misma zona, en los últimos 2.000 años. ${ }^{10}$ Por esta razón la secuencia sísmica del sector sur de la zona de subducción —el sur de Chile- ha recibido más atención que el centro y norte del país. Asimismo, dado que en el norte y centro de Chile no ha habido registro histórico de terremotos gigantes (igual o mayor que $9 \mathrm{Mw}$ ), se han buscado razones geológicas para explicarlo, argumentando que el contacto entre las placas varía a lo largo del país y que en la zona central o norte del país no existirían las condiciones para que ocurriese un terremoto gigante o megaterremoto como el llamado de Valdivia, de 1960. ${ }^{11}$

Para Chile, en general, y para cada segmento de la zona de subducción, en particular, es importante conocer y actualizar sus períodos de recurrencia, porque existe un principio geológico que dice que aquello que ha

relación entre desastres naturales y ocupación del territorio, así como la visión de los indígenas sobre los desastres naturales (2004 y 2006); y por último, a Virginia García, con la coordinación (en 1996, 1997 y 2008) de tres tomos que tratan la relación entre terremotos, desastres, y reacción de las sociedades.

7 Kanamori, 1983.

8 Barrientos, 2007.

9 Lomnitz, 1970 y 2004. Cisternas, 2005.

10 Cisternas, 2005. Cisternas et al., 2005.

11 Barrientos, 2007. 
ocurrido en la naturaleza una vez, volverá a suceder. ${ }^{12}$ Ello explica el interés que los sismólogos tienen en los registros escritos de las sociedades del pasado, así como en desarrollar la paleosismología, disciplina que podría advertir de territorios de los que no se tiene registro escrito u oral de eventos sísmicos de gran magnitud, pero en los que los ha habido.

En Chile metropolitano o central (que consideraremos situado entre las ciudades de La Serena y Rancagua - 30 a 34 grados de latitud sur-; que corresponde a la zona más tempranamente ocupada por los colonos españoles, y por lo tanto con más antigüedad de registros escritos, y más permanentes; y donde se concentra actualmente el $80 \%$ de la población nacional) no ha habido un terremoto gigante al menos desde que existen instrumentos para medirlos. Ello no descarta que hayan ocurrido antes de que pudiesen ser medidos, o antes del poblamiento español, o finalmente, del poblamiento humano en general. Además de suponerse, como ya hemos dicho, que el área de subducción donde se encuentra el centro de Chile es diferente a la de más al sur y no es capaz de generar terremotos gigantes, otra de las causas de la falta de atención a los terremotos grandes de Chile central es que parecieran repetirse a intervalos regulares y presentar un tamaño comparativamente moderado, con magnitudes que variarían entre 8 y $8.5 .{ }^{13}$ En esta secuencia se consideran los sismos de los años 1575, $1647,1730,1822,1906$ y $1985 .{ }^{14}$ Sin embargo, en los últimos años la frecuencia de la serie ha sido puesta en duda, porque no tendrían todos la misma «fuente» u origen ${ }^{15}$ — se ha argumentado que el de 1647 sería intraplaca, ${ }^{16}$ a diferencia de los del resto de la secuencia, que son interplaca-,${ }^{17} \mathrm{y}$ porque estaría incompleta: se agregó un terremoto ocurrido en $1580 .{ }^{18} \mathrm{De}$ esta manera, la secuencia de terremotos históricos en Chile metropolitano o central sería 1575, 1580 (posiblemente), 1730, 1822, 1906 y 1985.

12 Gould, 1984 y 1987. Ager, 1993. El primero en proponerlo fue Hutton, 1788.

13 Lomnitz, 1970 y 2004. Barrientos, 2007.

14 Idem. Kelleher, 1972. Comte et al., 1986.

15 Barrientos, 2007.

16 Hay dos grandes tipos de fuentes de terremotos en Chile: los interplaca, que ocurren en la zona de contacto entre las placas de Nazca y Sudamericana, y los intraplaca, que ocurren al interior de alguna de las dos placas. Leyton, Ruiz y Sepúlveda, 2010.

17 Se ha planteado que el terremoto de 1647 sería ajeno a recurrencia sísmica de Chile central, por haber sido generado por la falla andina y no costera. Cisternas, 2012.

18 Cisternas, Torrejón y Gorigoitía, 2012. Un documento hallado en el Archivo General de Indias (en adelante AGI) reporta ese terremoto: Carta del doctor López de Azoca, oidor de la Audiencia de Chile, Santiago, 11 de agosto de 1580, AGI, Chile 8, R. 13, N. 37. Sin embargo, es importante señalar que ese documento es la única noticia que se tiene de él. 
Por estas razones, parece oportuno reconsiderar la secuencia y detenerse en cada uno de esos sismos. Aunque de todos ellos hay registro documental, mientras más antiguos son los terremotos chilenos de la secuencia, menos conocidos son, y lo son menos aun en los territorios donde no había ciudades o estas eran poco importantes. Estas afirmaciones explican que en Chile la historia sísmica y la historiografía sobre los efectos de los terremotos se haya centrado en aquellos con buen corpus documental, como Valdivia 1960, Valparaíso 1906, Arica 1868 y Concepción 1751. De ellos el de $1730,{ }^{19}$ por su nivel de destrucción, ha sido considerado como el mayor de la secuencia mencionada, incluso por sus contemporáneos (que le llamaron «magno»), a pesar de ser pre-instrumental. ¿Es posible que el terremoto de 1730 haya sido el mayor de la serie e incuso gigante (mayor que $9 \mathrm{Mw})$ ?

Describirlo mejor no solo modifica el catastro sísmico, haciéndolo más riguroso y completo, con lo que se aporta también a la historia ambiental, sino que además contribuye, desde la descripción, al conocimiento histórico de Chile colonial, porque creemos que aun hace falta volver a las fuentes y recuperar los hechos poco o parcialmente conocidos. La relectura de todos los documentos que se han conservado hasta la actualidad de los testigos presenciales que lo describieron, ya conocidos (la mayor parte de su información fue recogida y compendiada por Montessus de Ballore en $1912^{20}$ y por Palacios), ${ }^{21}$ junto con nuevos documentos que hemos encontrado en archivos (el de Indias de Sevilla, de órdenes religiosas de Chile, y municipales), nos ha permitido conocer e interpretar mejor este evento geológico. La investigación paleosismológica — ejecutada en lugares que la documentación señalase como importantes-, podría reforzar la histórica. ${ }^{22}$

La hipótesis de esta investigación es que el terremoto de 1730 se diferencia del resto de la serie o secuencia ya referida, al ser un evento sísmico de gran envergadura, altamente destructivo y único, porque después no ha habido otro con similares características. Pensamos que es mayor de lo que se creía y que los demás porque los documentos dicen expresamente

19 Véase Gay, 1852. Barros Arana, 1884, II, 415-417; 1885, IV, 426-446; 1885, V, 18-21; 1886, VI, 62-74, 176-189; 1894, XIII, 742-747. Montessus de Ballore, 1912-1916. Palacios, 2009, 2012 y 2015. Valenzuela, 2012. Onetto, 2013, 50-66. Kordic, 1999. Firbas, 2009. Silgado, 1985. Urrutia de Hazbún y Lanza, 1993. Álvarez, 2014, 80-84.

20 Montessus de Ballore, 1912, 4, 73-93.

21 Palacios, en prensa [2016].

22 Carvajal y Gorigoitía, 2015. 
que la secuencia del sismo estuvo compuesta por dos terremotos grandes y dos tsunamis independientes, que ocurrieron con tres horas de diferencia, y a la misma hora en Santiago y Concepción, ciudades distantes entre sí 500 kilómetros; porque las fuentes reportan daños graves en la infraestructura en un territorio más extenso del que se había considerado, lo que indica que el tamaño de la ruptura fue mayor del que hasta ahora se había creído; y porque el tsunami penetró más metros al interior de lo que se pensaba hasta ahora, mostrando así que fue mayor.

\section{El primer terremoto $\mathrm{y}$ «salida de mar», 01:30 de la madrugada del 8 de julio de 1730}

De la hora precisa de los terremotos y tsunamis solo contamos con información de testigos presenciales de Santiago y Concepción, y de no presenciales de Valparaíso. No hemos hallado información cronológica proveniente de otras localidades.

Un primer movimiento fue reportado alrededor de la 01:30. En Concepción, el maestre de campo (gobernador de esa plaza militar), informó que el terremoto ocurrió a la 1 de la madrugada. ${ }^{23}$ El obispo de la ciudad lo reporta «como» a la 01:30. ${ }^{24}$ Un jesuita, también testigo ocular y autor anónimo de un escrito cuyo título comienza como «Relación del lastimoso», también señala la una de la mañana para el comienzo del primer sismo. ${ }^{25}$ Las tres fuentes coinciden en que el movimiento, aunque largo en duración, no fue muy recio y no provocó daños de importancia. A pesar de ello, este terremoto fue capaz de generar una salida de mar en la bahía de Concepción, lo que indica su gran tamaño. De acuerdo al jesuita recién citado, inmediatamente después del primer movimiento:

se supo después por el dicho de unos pescadores que, teniendo tendidas en el mar sus redes, despiertos con el temblor fueron a reconocerlas, desde esta hora empezaron a retirarse para adentro sus aguas, señal cierta de su salida pues, revolviendo dobladas

23 Carta del maestre de campo Manuel de Salamanca sobre el terremoto de Concepción, Concepción, 10 de julio de 1730, Archivo Nacional Histórico de Chile (ANH), Fondo Claudio Gay, 18. Chile, 145 .

24 Relación del obispo de la Concepción al rey, Concepción, 20 de agosto de 1730, AGI,

25 «Relación del lastimoso y horrible estrago de la ciudad de la Concepción del reino de Chile, causado del temblor e inundación del mar que anegó el día 8 de julio de 1730», Concepción, s/f., ANH, Colección Sergio Fernández Larraín, 23. Ha sido publicado por Valenzuela, 2012, 214-224, cita 216. El original se encuentra en el Archivum Romanum Societatis Iesu de Roma, Provincia Chilensis, vol. 5. 
y con mayor ímpetu entrando por la boca del río y rebalsando por las calles, anegaron las casas vecinas, la guardia y casi todo el palacio con inundación tan repentina que fue ella la primera que haciéndose sentir dio el aviso de sí misma. ${ }^{26}$

En Santiago, el gobernador de Chile, Gabriel Cano y Aponte, reportó que el primero ocurrió entre la 01:00 y 02:00 y que duró «cerca de medio cuarto de hora». ${ }^{27}$ Otra relación jesuita anónima, cuyo título comienza con «Relación del espantoso», describe que el primer sismo ocurrió a la 01:30, «poco más». ${ }^{28} \mathrm{El}$ gobernador reporta que no fue con tanta violencia como para ocasionar ruina; mientras que un informe de siete meses más tarde, de febrero de 1731, relata que el movimiento fue «tan formidable que ninguno hubo que no se vistiese y saliese». ${ }^{29} \mathrm{La}$ «Relación del espantoso» describe un movimiento suave pero alertador.

\section{El segundo terremoto y tsunami, tres horas después}

El segundo sismo se desencadenó «como» a las 03:00, según el obispo de Concepción, y «cerca del amanecer» de acuerdo al jesuita autor de la «Relación del lastimoso», sin decir una hora. Sorprende que el maestre de campo no mencionase este terremoto, sino solo el primero. Según el jesuita que describió el terremoto en Concepción, este segundo movimiento duró más que el precedente, y fue «tan recio sacudimiento que casi no se podía estar en pie, haciéndose necesario buscar algún arrimo para mantenerse, como que la tierra nos quisiese atajar la huida, negándonos la acogida que en ella buscábamos». ${ }^{30} \mathrm{~A}$ este terremoto también le siguió una salida del mar, que fue más descrita que la primera por los testigos. Aun así, todo el tsunami se describe como un proceso continuo desde el sismo de la 01:00, habiendo traspasado el mar la costa varias veces, retirándose y entrando, hasta la tarde de aquel día.

26 Idem.

27 El gobernador de Chile al virrey del Perú, Santiago, 20 de julio de 1730, ANH, Fondo Benjamín Vicuña Mackenna, 340-C.

28 «Relación del espantoso terremoto que arruinó la ciudad de Santiago de Chile el día 8 de julio en el año de 1730», en Valenzuela, 2012, 203-214, cita 204. Esta relación es anónima y en el texto se lee que fue escrita el día 12 de octubre de 1730. El original se encuentra en el Archivum Romanum Societatis Iesu de Roma, Provincia Chilensis, vol. 5.

29 «Informe que con varios testimonios hace el obispo de Santiago de la ruina que ha padecido esta ciudad con los primeros terremotos del día 8 de julio del año de 1730 y siguientes en más de dos meses. Santiago de Chile, febrero 20 de 1731», en Gay, 1852, 478.

30 «Relación del lastimoso y horrible...», Concepción, s/f., ANH, Colección Sergio Fernández Larraín, 23. 
En Santiago, el segundo sismo, según Cano y Aponte, fue a las 05:00, duró lo mismo que el primero y tuvo «mayor fuerza», ${ }^{31}$ es decir, liberó una cantidad mayor de energía. El cabildo de Santiago lo fijó a las 04:00 y menciona que ese, y no el primero, fue el más destructivo. ${ }^{32}$ Otro informe señala que fue «tan espantoso que no daba lugar el movimiento de la tierra a mantenerse en pie a ninguno de sus habitadores». ${ }^{33} \mathrm{La}$ «Relación del espantoso» reportó que fue tres horas después que el primero, que señaló a las 01:30, es decir, a las 04:30, y lo calificó como «espantoso terremoto, cuya violencia en el movimiento, entre todos los temblores que habían experimentado los vivos, pudo calificarlo por el primero, si ya el tiempo o por mejor decir la piedad no le hubiera hecho el segundo» ${ }^{34}$ dice quizá refiriéndose al devastador terremoto de Santiago de 1647. Fray Francisco Seco escribe que fue «como» a las 04:00, mayor y más terrible que el anterior, y fue el que derribó los edificios. ${ }^{35}$ Sin citar su fuente de información, la Gazeta de México escribió que fue a las 05:00, que arruinó «en un todo» la ciudad, siendo «el mayor que se ha experimentado desde que está en poder de Españoles». ${ }^{36}$

En Santiago se percibió un tercer movimiento a mediodía, aunque — dice el gobernador de Chile- fue con menos «vigor». La Gazeta de México dice de él lo mismo que el gobernador; el obispo de la ciudad lo señala entre las 12:00 y 13:00, pero dice que fue mayor al de las 04:00. ${ }^{37}$ Es interesante que en Concepción no se mencione este tercer movimiento. Los sismos se repitieron aquel día y durante los dos meses siguientes.

Aunque la bibliografía señala que hubo dos terremotos esa noche, se ha supuesto que el primero fue alertador y el segundo fue el destructivo. La lectura detallada de los documentos conocidos muestra que aun cuando el primero (01:30) haya sido menor que el segundo (04:30), su tamaño fue lo suficientemente grande como para generar un tsunami que inundó parte de

31 El gobernador de Chile al virrey del Perú, Santiago, 20 de julio de 1730, ANH, Fondo Benjamín Vicuña Mackenna, 340-C.

32 Acta del cabildo de Santiago, 19 de julio de 1730, en Actas del Cabildo de Santiago 29 (en adelante ACS), publicadas en Colección de Historiadores de Chile y de Documentos relativos a la Historia Nacional, 52, Santiago, Instituto Chileno de Cultura Hispánica, 1975, 59.

33 Memorial de fray Francisco Seco, lector jubilado, procurador general de la orden de San Francisco por lo tocante a las provincias de los reinos de Indias, Sevilla, 12 de agosto de 1731, AGI, Chile, 145.

34 «Relación del espantoso...», en Valenzuela, 2012, 204.

35 Francisco Seco, cit. en nota 33.

36 Gazeta de México, abril de 1731, en Gacetas de México, 1949, I, 322. Se basa en esa Gaceta para informar sobre el terremoto: Murillo Velarde, 1752, 311.

37 Informe del obispo de Santiago, 1731, en Gay, 2, 1852, 478. 
Concepción. Asimismo, la intensidad de cada uno de ellos se percibió como igual en Santiago y Concepción, distantes 500 kilómetros entre sí, lo que da cuenta de su fuerza. Además, un documento no considerado hasta ahora podría acreditar que también en la ciudad de La Serena se diferenciaron al menos dos terremotos (y no uno, como dicen los demás documentos que mencionan a La Serena): un vecino reportó que la ruina de la ciudad había sido ocasionada por «los repetidos temblores» del año $1730 .{ }^{38}$ Fueron dos (y no solo uno) movimientos que liberaron gran cantidad de energía, que generaron tsunamis independientes entre sí. De otras localidades costeras, incluyendo las dos que estaban densamente pobladas, Valparaíso y La Serena, no tenemos información respecto a la hora de la inundación, y de si ambos lo hicieron o solo uno de ellos. Solo podemos afirmar en base a los documentos y los relatos de testigos que fueron dos para el caso de Concepción.

El segundo de ellos fue mayor que el primero, y tanto que no permitía que las personas se mantuviesen en pie ni en Concepción ni en Santiago.

\section{El terremoto fue destructivo a lo largo de al menos 1.200 kilómetros}

Pocos días después del terremoto (en rigor, de los terremotos) del 8 de julio de 1730 las fuentes reportaban: «alcanzó la conmoción de tierra a todo el reino», «la desdicha de este reino» y «la ruina que padecieron las ciudades de aquel reino» ${ }^{39}$ El daño, se dice, abarcó a todo el reino de Chile, que por entonces contaba con pocas ciudades (La Serena, Santiago y Concepción, ${ }^{40}$ situadas en casi en la misma graduación longitudinal y separadas entre sí por mil kilómetros en línea recta) y muchas localidades o poblaciones informales, dispersas, cuyo origen era la agrupación de casas al interior de haciendas, antiguos pueblos de indios, población en torno a conventos rurales, y asientos mineros. Por esta razón, la información sobre

38 Expediente seguido por Juan Cristóbal Bórquez sobre naturalización, La Serena 1740, ANH, Fondo Municipalidad de La Serena, vol. 5.

39 Relación de obispo de Concepción al rey, Concepción, 20 de agosto de 1730, AGI, Chile, 145. Carta del gobernador de Chile al rey, Santiago, 20 de julio de 1730, AGI, Chile, 145. Auto del virrey del Perú con ocasión del terremoto de 1730, Lima, 20 de septiembre de 1730, ANH, Fondo Antiguo, 6 .

40 Valparaíso no era aun ciudad, sino el puerto de Santiago, y no tenía cabildo ni, por lo tanto, vecinos. Aunque Quillota había sido fundada en 1717, no se consiguió que los vecinos se trasladasen al sitio de la ciudad (el gobernador de Chile dijo que nada más fundada, los vecinos se retiraron a sus haciendas) y el gobernador Manso de Velasco la refundó en la década 1740. 
los efectos del terremoto es mayor en las ciudades más importantes (Santiago y Concepción), menor en el puerto de Valparaíso, un simple dato en algunas ciudades pequeñas o localidades que tenían iglesia y convento, $\mathrm{y}$ casi inexistente en lugares rurales intermedios (figura 1C).

El margen norte de efectiva ocupación del reino hacia 1730 era el poblado de Copiapó ( $27^{\circ} 32^{\prime}$ latitud sur), límite meridional del desierto de Atacama (figura 1C), perteneciente a la Audiencia de Charcas. Localizado a 680 kilómetros al norte de Santiago, el valle de Copiapó estaba prácticamente despoblado, excepto por pequeños oasis de antigua ocupación indígena. Originalmente, Copiapó era un antiguo pueblo de indios, sin ciudad formalmente fundada y con poca población. En 1707 se descubrieron ricas vetas de oro y plata que promovieron su crecimiento, por lo que en 1713 ya contaba con 900 habitantes dedicados principalmente a trabajar en los trapiches de los alrededores. Solo catorce años después del terremoto de 1730, se encomienda la traza y fundación de la ciudad. ${ }^{41}$ De este modo, es difícil esperar información relativa al terremoto desde ese poblado o desde los trapiches.

Montessus de Ballore puso de manifiesto que el límite septentrional de los efectos del terremoto había sido La Serena, por no haber encontrado documentación de zonas más al norte, pero reconoció que podrían haberse extendido más en esa dirección. ${ }^{42}$ En su reciente libro, que contiene la descripción de todos los terremotos importantes de Chile hasta fines del siglo XIX, Alfredo Palacios reafirma la idea de que «se propagó entre Coquimbo y Concepción».43

Para 1730 ya existía un convento franciscano en Copiapó, y por el fraile Francisco Seco se sabe que dicho convento fue arruinado «hasta sus cimientos» ${ }^{44}$ dato que no había sido considerado, hasta ahora, para extender hacia el norte los daños en infraestructura, como tampoco el que cinco años después, en 1735, el provincial franciscano confirmase también la «ruina» de ese edificio por efecto del terremoto. ${ }^{45} \mathrm{~A}$ esta información, conocida pero no considerada en lo referente a Copiapó, agregamos un documento que hemos hallado: el testimonio del recorrido que realizó el

41 Galdames, 1966, 146.

42 Montessus de Ballore, 1912. Que el límite septentrional del daño fuese La Serena fue recogido por los estudios posteriores: Lomnitz, 1970 y 2004; Comte et al., 1986.

43 Palacios, 2015, 96.

44 Memorial de fray Francisco Seco, cit. en nota 33.

45 El ministro de la provincia de Chile de la orden de San Francisco al rey, Santiago, 27 de abril de 1735, AGI, Chile, 145 . 
A

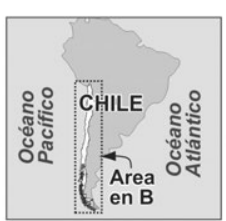

B

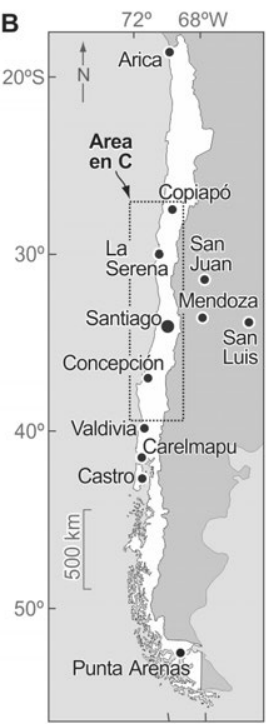

$\mathrm{C}_{27^{\circ}}$

29

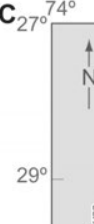

$72^{\circ}$

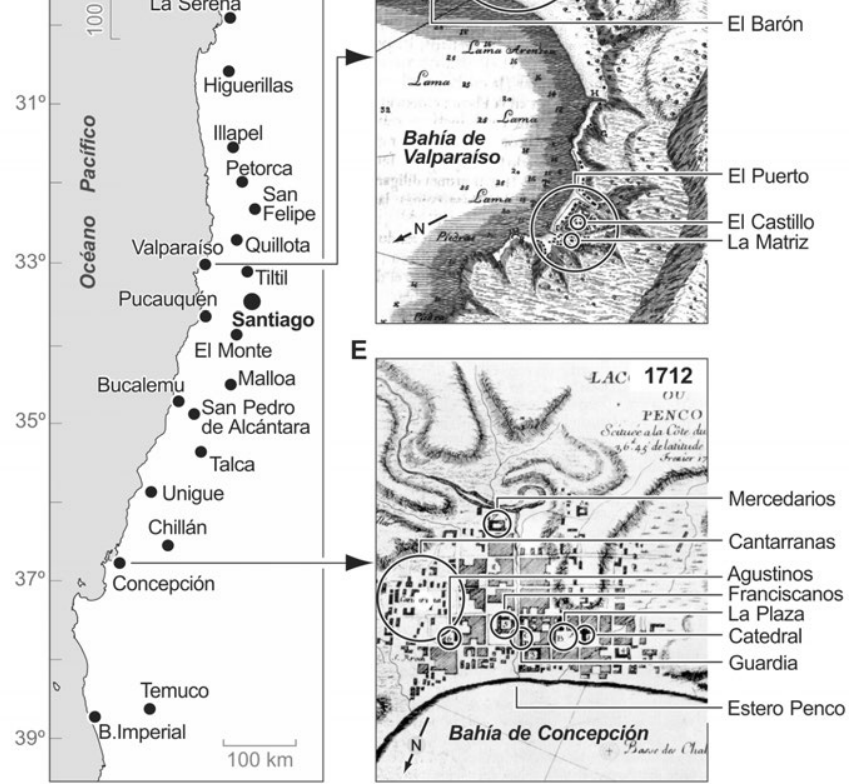

Figura N.$^{\circ}$ 1. Localización de Chile y de los lugares mencionados en el texto. A) Contexto de Chile en Sudamérica. B) Chile actual con la localización de los lugares mencionados en las fuentes documentales, incluyendo tres ciudades trasandinas. C) Localización de los principales topónimos utilizados en el siglo XVIII y mencionados en el texto. D) Plano de la ensenada y puerto de Valparaíso, 1744, de Jorge Juan y Antonio de Ulloa, Relación histórica del viaje a la América Meridional, Madrid, Antonio Marín, 1748. En él diferenciamos el Almendral del Puerto. E) Plano de Concepción identificando sus principales construcciones hacia 1712; las que serían posteriormente afectadas durante el tsunami de 1730 . Hecho sobre la base del grabado de Amadeo Frezier, "Plan de la ville de la Conception ou Penco", en Relation du voyage de la mer du sud aux cotes du Chily et du Perou, fait pendants des années 1712, 1713 y 1714, París, Chez Jean-Geoffroy Nyon, 1716.

Fuente: Elaboración propia. 
recién nombrado obispo de Santiago, Juan Bravo de Rivero, desde Alto Perú hasta la capital del reino, cuando en 1736 viajó para tomar posesión del obispado (figura 1C). Cruzó la cordillera a la altura de Copiapó y avanzó hacia el sur, observando a lo largo de toda la ruta «los estragos que causó el terremoto del año 30, principalmente en las parroquias...». ${ }^{46}$ Esta es la única fuente disponible que reporta daños entre Copiapó y La Serena por efecto del terremoto de 1730. Desafortunadamente, el obispo no menciona topónimos que permitan localizar los lugares específicos. Con él podemos confirmar que dañó infraestructura hasta al menos Copiapó.

Más al sur se situaba la ciudad y puerto de La Serena (29 ${ }^{\circ} 54^{\prime}$ latitud sur), llamada por entonces indistintamente La Serena o Coquimbo. El territorio entre Copiapó y La Serena era estepárico y sin poblados. Respecto a lo acontecido en esta última ciudad, localizada 470 kilómetros al norte de Santiago y asentada en una alta terraza, el cura párroco, Melchor de Jáuregui y Carrera, sintió «los desusados y nunca experimentados movimientos, cayendo a su violencia las casas, y lo más sensible, los sagrados templos» ${ }^{47}$ Agregamos lo que consta en un documento municipal de 1740, no considerado hasta ahora, en el que el vecino Juan Cristóbal Bórquez reportó que la ciudad había padecido «ruina general», que estaba la mayor parte «demolida», debido a «los repetidos temblores» de $1730 .^{48}$ Francisco Seco informó que el convento franciscano de la ciudad fue arruinado hasta sus cimientos. ${ }^{49}$ Otro documento recientemente encontrado indica que la iglesia y convento dominico habían quedado «arruinados». ${ }^{50}$ Mucho más tarde, en 1796, se informó que las murallas de La Serena y puerto de Coquimbo fueron destruidas por el sismo de $1730 .{ }^{51}$ Por lo tanto, en La Serena y su puerto, Coquimbo, el terremoto fue muy destructivo: derribó casas, las murallas de la ciudad, y dejó iglesias y conventos arruinados hasta sus cimientos.

Avanzando hacia el sur, se refiere que un convento franciscano, situado por entonces en un paraje llamado Higuerillas (cercano a la actual ciudad de Ovalle, $30^{\circ} 34^{\prime}$ de latitud sur), se salvó del terremoto, pero solo por

46 El obispo de Santiago de Chile al rey, Santiago, 30 de diciembre de 1736, AGI, Chile, 150.

47 Melchor de Jáuregui y Carrera, cura de La Serena, informa al rey, La Serena, 14 de abril de 1733, AGI, Chile, 145.

48 Expediente seguido por Juan Cristóbal Bórquez, cit. en nota 38.

49 Francisco Seco, cit. en nota 33.

50 Razón de las noticias de la provincia de San Lorenzo Mártir de Chile, Santiago, 1742, Archivo Provincial de la Orden de Predicadores en Santiago de Chile, Convento de Santo Domingo (APSD), Libro de Comunicaciones Oficiales de la Provincia de San Lorenzo Mártir (LCO).

51 Carvallo y Goyeneche, [1796] 1875, 253. 
estar recién construido. ${ }^{52}$ Siguiendo, Cano y Aponte informó que los asientos mineros de Illapel ( $31^{\circ} 37^{\prime}$ latitud sur), Petorca ( $32^{\circ} 15^{\prime}$ latitud sur) y Til Til ( $33^{\circ} 04^{\prime}$ latitud sur), «y otros, han quedado incapaces y sin trapiches $\gg^{53}$ (figura $1 \mathrm{C}$ ). Aunque se reporta daño en la infraestructura minera, no se mencionan las habitaciones; sin embargo, es probable que aquellas fuesen campamentos de construcción liviana. No consta la existencia de iglesias ni conventos y solo hacia finales del siglo se fundarán villas para congregar a la población dispersa en esa y otras zonas.

Es difícil también conseguir información sobre el valle de Aconcagua y alrededores. Allí existían haciendas, «lugares» y conventos, pero no ciudades fundadas, excepto la de Quillota ( $32^{\circ} 52^{\prime}$ latitud sur), que existía en el papel (véase la nota 40). De acuerdo a Francisco Seco, el convento franciscano de Quillota quedó totalmente arruinado, y según un historiador jesuita que escribió en 1891, también fueron destruidos aquí la iglesia y convento de su orden. ${ }^{54}$

En el valle de Aconcagua, en la localidad de San Felipe, de antigua población que fue congregada como villa recién en $1740\left(32^{\circ} 45^{\prime}\right.$ latitud sur), un convento mercedario «quedó reducido [...] a solo terreno lleno de los despojos de la ruina». ${ }^{55}$ En sus cercanías, de acuerdo a fray Francisco Seco, el convento franciscano también se arruinó, y en el vecino Curimón ocurrió lo mismo con el convento dominico de Santa Rosa $\left(32^{\circ} 45^{\prime}\right.$ latitud sur), dato que no había sido mencionado. ${ }^{56} \mathrm{El}$ obispo Bravo de Rivero escribió que todas las iglesias entre San Felipe y Santiago quedaron maltratadas. ${ }^{57}$

Hacia el oriente, al otro lado de la cordillera de los Andes, en la provincia de Cuyo, jurisdicción del reino de Chile, existían las ciudades de Mendoza ( $32^{\circ} 54^{\prime}$ latitud sur y $68^{\circ} 50^{\prime}$ longitud oeste), San Juan de la Frontera ( $31^{\circ} 31^{\prime}$ latitud sur y $68^{\circ} 31^{\prime}$ longitud oeste), y San Luis (33 $18^{\prime}$ latitud sur y $66^{\circ} 20^{\prime}$ longitud oeste), fundadas a mediados del siglo XVI,

52 Coenen, 1995, 73. Aunque es una publicación reciente y el autor no cita su fuente, se sabe que este escribió su libro teniendo documentación franciscana antigua a la vista, por eso no nos pareció descartable.

53 Copia de la carta del gobernador de Chile al virrey del Perú, Santiago, 20 de julio de 1730, AGI, Chile, 145.

54 Enrich, II, 1891, 144

55 Noticias de fray Pedro Romo, comendador del convento de la orden de la Merced de San Felipe el Real, San Felipe, 28 de septiembre de 1744, AGI, Chile, 137.

56 El procurador general de la provincia se dirige al rey informando del desastre causado por el terremoto de Santiago en 1730, Santiago, 22 de noviembre de 1732, APSD, LCO.

57 El obispo de Santiago de Chile al rey, Santiago, 30 de diciembre de 1736, AGI, Chile, 150. 
y otras pequeñas poblaciones dispersas (figura 1B). Entre vecinos e indios, las tres ciudades sumaban unas 10.000 personas, principalmente dedicadas a la agricultura. Para Mendoza (a unos 180 kilómetros al este de Santiago), podemos mostrar el siguiente panorama: cayó al suelo la iglesia parroquial ${ }^{58}$ el convento franciscano no cayó, pero sufrió severos daños y hacia 1735 aun amenazaba derrumbarse..$^{59}$ Además, la Relación del obispado del año 1744 señala que Mendoza quedó «desmantelada» junto a sus templos. ${ }^{60}$ Aportamos aquí la información del obispo Bravo de Rivero: el terremoto de 1730 no afectó a las iglesias de las ciudades más orientales de San Juan y San Luis (figura 1B).

Al poniente, en el territorio insular, el archipiélago de Juan Fernández estaba deshabitado y no sería ocupado hasta 1750, cuando se fundó un fuerte y se estableció población permanente, arrasada, por cierto, por el tsunami de $1751 .{ }^{61}$

Santiago ( $33^{\circ} 23^{\prime}$ latitud sur) y sus alrededores eran la zona más poblada del reino. Respecto al sismo de aproximadamente las 4:30 de la madrugada, su cabildo informa que la ciudad quedó completamente arruinada. ${ }^{62}$ Quedaron en «ruina» los edificios de la cárcel, la real audiencia y el cabildo ${ }^{63}$ En cuanto a los edificios religiosos, el gobernador informa la ruina de la mayoría de las iglesias: «quedaron por tierra» las iglesias y conventos de los monasterios de Santa Clara, donde se hundió su iglesia, la parte superior de la torre, y se cayeron las paredes; de las agustinas; del convento de Santo Domingo, en que «no quedó piedra sobre piedra»; la iglesia del convento mercedario de San José, que se arruinó completamente. ${ }^{64}$ Aportamos al conocimiento que se tenía hasta ahora el reporte de la visita del padre provincial mercedario: «la iglesia que teníamos más es para llorar al referirla que para inventariarla, pues se halla toda en el suelo con

58 Relación del obispado de Santiago de Chile por Joseph Fernández de Campino, Santiago, 14 de junio de 1744, ANH, Fondo Antiguo, 34. El obispo de Santiago de Chile al rey, Santiago, 1738, AGI, Chile, 150.

59 El gobernador de Chile al rey, Santiago, 28 de abril de 1731, AGI, Chile, 145.

60 Relación del obispado de Santiago de Chile por Joseph Fernandes de Campino, Santiago, 14 de junio de 1744, ANH, Fondo Antiguo, 34.

61 El terremoto y tsunami del 25 de mayo de 1751 afectó principalmente la antigua ciudad de Concepción, luego de lo cual fue trasladada a otro sitio, como consecuencia de la destrucción provocada y la histórica pérdida de vidas y edificios por fenómenos como este. En las islas Juan Fernández, el tsunami arrasó con la corta población allí instalada, causando 38 muertes. Montessus de Ballore, 1912, IV, 94-116. Palacios 2012, 29-36.

62 Acta del cabildo de Santiago, 19 de julio de 1730, ACS, 59.

63 Francisco Seco, cit. en nota 33.

64 Carta del gobernador de Chile al Rey, Santiago, 20 de julio de 1730, AGI, Chile, 145. 
todas sus alhajas perdidas, y el altar mayor se hizo pedazos con el terremoto», porque se cayeron las bóvedas de las tres naves, que eran de ladrillo. ${ }^{65}$ El convento mercedario de San Miguel también se arruinó. Se hundió la torre con el reloj del convento principal de los franciscanos en Santiago, y tuvo varias murallas derribadas. ${ }^{66}$ El franciscano de la Santa Recolección quedó «lastimosamente asolado», al igual que su colegio, el de San Diego, en la Cañada, aunque ambos, se dice, susceptibles de ser reconstruidos. ${ }^{67} \mathrm{La}$ catedral, aunque muy dañada, no cayó. Hubo otros conventos más pequeños dañados, con sus iglesias incapaces de celebrar misas. Sobre las viviendas particulares, la mayoría de las casas de la ciudad tuvieron «ruina total», solo algunas quedaron capaces de arreglo, y la gente las abandonó cobijándose bajo toldos en la plaza, cañada y arrabales. ${ }^{68}$ En suma, el sismo hizo caer hasta los cimientos de las casas y edificios de la ciudad, probablemente con similar intensidad que en Concepción.

En el puerto de Santiago, Valparaíso ( $33^{\circ}$ latitud sur), la reducida población civil y militar ocupaba el estrecho pie de cerro del puerto, y la primera terraza de los cerros más cercanos, alrededor del castillo de San José (figura 1D). Dice la «Relación del espantoso» — no distinguiendo expresamente los dos movimientos- que el terremoto se sintió con violencia y que los edificios que no fueron afectados por el posterior o posteriores tsunamis, quedaron «casi inservibles» por el sismo, salvándose solo la iglesia de la orden de San Agustín. ${ }^{69}$ Compulsando los documentos, tenemos que la iglesia mayor o matriz cayó, quedando completamente inutilizada, ${ }^{70}$ aportamos

65 Visita Provincial del Convento de San José, Santiago, 23 de abril de 1733, Archivo Provincial de la Orden Mercedaria de Chile (APOM), Visitas Convento Grande 1714-1843/ Convento San Miguel 1722-1769/ Cautivos 1840-1848.

66 Gazeta de México, abril de 1732, en Gacetas de México, 1950, II, 24-25.

67 El ministro de la provincia de Chile de la orden de San Francisco al rey, Santiago, 27 de abril de 1735, AGI, Chile, 145.

68 José Fernández Montero, en nombre del convento antiguo de monjas de Santa Clara. Concepción, 22 de enero de 1735, AGI, Chile, 145.- Carta del padre provincial Rodrigo de Covarrubias, Santiago, 20 de septiembre de 1731, APOM, Cesiones y capellanías. Siglo XVIII principalmente.Visita Provincial del Convento de San José, Santiago, 23 de abril de 1733, APOM, Visitas Convento Grande 1714-1843/ Convento San Miguel 1722-1769/ Cautivos 1840-1848.- «Relación del espantoso...», en Valenzuela, 2012, 212.- El ministro de la provincia de Chile de la orden de San Francisco al rey, Santiago, 27 de abril de 1735, AGI, Chile, 145.- Sor María Bernarda, abadesa de las Capuchinas de la Santísima Trinidad de Chile, al rey, Santiago, 2 de diciembre de 1732, Archivo del Arzobispado de Santiago (AAS), Fondo Gobierno, 37.

69 «Relación del espantoso...», en Valenzuela, 2012, 208.

70 Carta de Joseph del Pozo y Silva al rey, Valparaíso, 26 de octubre de 1745, AAS, Fondo Gobierno, 31. También en AGI, Chile, 154. 
que también lo hizo la franciscana, ${ }^{71}$ y una pequeña capilla jesuita, junto con las viviendas de sus religiosos. ${ }^{72}$ Todas estas iglesias estaban al pie de los cerros. Asimismo, las construcciones militares estaban en la terraza inferior del cerro que se llama del Castillo, de las que cayeron el castillo del gobernador, hecho de adobe, las salas de guardia, almacenes de pólvora y calabozos, construidos de cal y piedra. Una visita posterior, no mencionada hasta ahora para describir este terremoto en Valparaíso, constató que «fueron arrancadas desde su cimiento» las murallas de la sede de gobierno y las escalas de piedra que daban acceso al cerro y al castillo, que «fueron tronchadas y reducidas a fragmentos». ${ }^{73}$ En síntesis, el terremoto en Valparaíso, por entonces restringido a la playa frente a la actual iglesia La Matriz y a los cerros inmediatos, fue altamente destructivo. Aunque no tenemos información de los efectos de la sacudida en el Almendral, una planicie arenosa pobremente habitada por ese entonces, sí sabemos que fue cubierta por el mar (figura 1C).

En los alrededores de Santiago, se informa que las haciendas del reino quedaron «desoladas», declarando sus dueños la ruina total. Se describe que en los campos vecinos el estrago fue mayor que en Santiago,

pues arrancó casas enteras desde los cimientos, abrió disformes zanjas en la tierra, brotando por alguna de ella cantidad de agua de pestilencial olor, y aun hubo noticia cierta de haberse mudado de un lugar a otro bien distante un monte entero, viéndose otros despoblados de robustísimos troncos de árboles que arrancó de raíz la violencia del movimiento. ${ }^{74}$

Hacia el sur de Santiago no existían ciudades hasta la pequeña Chillán ( $36^{\circ} 36^{\prime}$ latitud sur), localizada 400 kilómetros más al sur. Entre Santiago y ella se desarrollaba la agricultura del reino, y aunque su población era importante tenía una fuerte impronta rural y vida centrada en la hacienda. ${ }^{75}$ La mayoría de las órdenes religiosas tenían conventos, iglesias y haciendas

71 Expediente del pleito sobre traslación de la cofradía del Rosario a nuestro convento de Valparaíso. Año 1753, APSD, Carpetas Convento de Santo Domingo.

72 «Relación del espantoso...», en Valenzuela, 2012, 208.

73 Residencia de José de la Torre, Valparaíso, 1735, AGI, Escribanía, 942A. Vicuña, 1936, 603-604. Vicuña cita la «vista de ojos» de La Torre Verdugo, asociado del oficial real o teniente de veedor Lorenzo de la Piedra, del escribano José de Euguit, del capitán Francisco Arnous Loriel, maestro mayor de arquitectura, y del maestro mayor de carpintería José del Bore. Y dice: «Este documento se encuentra original en el protocolo del escribano citado archivado en la oficina de don Máximo Navarrete».

74 «Relación del espantoso...», en Valenzuela, 2012, 207.

75 Lorenzo, 2013. 
en esos campos (figura $1 \mathrm{C}$ ). Muchos de ellos quedaron «arruinados». Fray Francisco Seco reporta la ruina de los conventos de San Francisco del Monte, San Pedro de Alcántara, Malloa (ambos en el valle de Colchagua), y Unigüe (al norte de Chillán); hacia 1735 los religiosos aun habitaban en chozas. Los dominicos también declaran graves daños en sus haciendas rurales. A unos 120 kilómetros de Santiago, la estancia llamada Pucauquén en «la costa de San Antonio» (33 $35^{\circ}$ ' latitud sur), se arruinó totalmente, aunque era nueva y costosa. Se cayeron hasta las paredes y cimientos, y se perdieron «con su ruina todas las maderas y demás materiales, sin haber quedado cosa de algún provecho» ${ }^{76}$ Vecina estaba la estancia de Bucalemu, que pertenecía a los jesuitas. Allí se derribó gran parte de la iglesia, «y paró tan mal lo restante que fue preciso edificarlo de nuevo», ${ }^{77}$ se dice en 1891. Finalmente, a unos 350 kilómetros al sur de Santiago, y a alrededor de 120 al norte de Chillán, en la estancia dominica de Cauquenes, se arruinaron todos su edificios ${ }^{78}$ información que podemos aportar como nueva.

En la ciudad de Chillán, 400 kilómetros al sur de Santiago, fue la ruina total de los conventos dominico y franciscano. ${ }^{79}$ La zona entre Chillán y Concepción era de haciendas agrícolas y ganaderas, pero con un acento de territorio pre-fronterizo. Concepción, asentada por ese entonces en el sitio de Penco ( $36^{\circ} 46^{\prime}$ latitud sur), era la segunda ciudad del reino. Ambos terremotos fueron tan importantes que provocaron dos tsunamis. Debido a que el mar salió inmediatamente después de cada uno de los dos sismos, es difícil diferenciar la principal causa de la destrucción de la ciudad.

Al sur de Concepción no existía población española - excepto los fuertes de la frontera del Bío Bío cercanos a Concepción (figuras 1B y 1C) — desde 1598, año en que mapuches y huilliches se levantaron contra el dominio español, expulsando a los colonos y fijando el río Bío Bío como límite entre ambos «estados», a 500 kilómetros al sur de la capital. Así, el territorio entre el Bío Bío y los fuertes de Carelmapu y Calbuco $\left(41^{\circ}\right.$ latitud sur, atendidos desde la provincia de Chiloé), conocido como «la frontera» o «Estado de Arauco», estaba ocupado por población indígena que vivía en agrupaciones dispersas. ${ }^{80}$ Ya sea porque allí el tamaño del sismo

76 Certificación de Miguel de Salinas, Pucauquén, 25 de noviembre de 1730, AGI, Chile, 145.

77 Enrich, II, 1891, 144

78 El procurador general de la provincia al rey, Santiago, 22 de noviembre de 1732, APSD, LCO.

79 Francisco Seco, cit. en nota 33.

80 Bengoa, 2008. 
fue menor o por la falta de presencia de población hispano-criolla, no se cuenta con reportes de daños generados en 1730. Además, es poco probable que dañara las ligeras viviendas de los mapuches. A pesar de esto, contamos con una escueta referencia de daño en la costera Valdivia $\left(39^{\circ} 48^{\prime}\right.$ latitud sur), refundada en 1645 como plaza fuerte en medio de territorio indígena, y que hacia 1730 contaba con vecindario civil. ${ }^{81}$ En un reporte fechado en 1731 se informa que tuvo «ruina». ${ }^{82}$ Sin embargo, no tenemos referencia a él en la documentación propia de la plaza, por lo que decir ruina de la ciudad podría ser superlativo. Más al sur de Valdivia, como hemos dicho, no había poblados sino hasta los fuertes chilotes de tierra firme: Carelmapu y Calbuco, y al sur de ellos se extienden por 2.300 kilómetros los archipiélagos patagónicos, hasta el confín del continente. Al extremo norte de ellos, en la isla de Chiloé, el puerto de Chacao y la ciudad de Castro $\left(42^{\circ} 28^{\prime}\right.$ latitud sur) eran los únicos asentamientos de españoles (figura 1B). Sin embargo, no se conocen reportes que mencionen la percepción del sismo de 1730.

De esta manera, mediante el obispo citado Bravo de Rivero podría confirmarse que el terremoto de 1730 fue destructivo en infraestructura al menos hasta Copiapó, y por lo tanto lo fue por al menos 1.200 kilómetros (entre esta ciudad y Concepción); 200 más que los 1.000 (entre La Serena y Concepción); ${ }^{83}$ más que la extensión entre 350 y 550 que sostienen otros $;{ }^{84}$ y más que cualquier otro registrado en Chile, excepto el de 1960. Se acredita también que fue destructivo hasta Mendoza. Aunque lo que vio y escribió el obispo no es la primera noticia que tenemos de la destrucción en Copiapó y Mendoza, esta permite acreditarlo y asentarlo.

Pero además, de acuerdo a la situación poblacional de Chile por entonces, es posible afirmar que la extensión territorial de los efectos del terremoto de 1730 fue mayor que la reportada en los documentos, que solo dan cuenta de las ciudades y los lugares de interés económico o religioso, pero no de los poblados secundarios. Por otro lado, es evidente que la documentación generada por las autoridades de Santiago y Concepción y por las órdenes religiosas que lamentaban la ruina de sus iglesias y conventos rurales, da cuenta de la destrucción allí donde había edificios importantes, pero no refleja las pérdidas de construcciones particulares, dispersas en el reino,

81 Guarda, 2001.

82 Gay, 2, 1852, 484.

83 Palacios, 2015, 96.

84 Montessus de Ballore, 1912. Barrientos, 2007. Lomnitz, 1970 y 2004. Comte et al., 1986. 
de adobe y un solo piso, como era la costumbre de edificación, y mucho menos los «lugares» de indios en los oasis del desierto al norte y alrededores de Copiapó, y al sur, en el «Estado de Arauco». Queda abierta, por lo tanto, la posibilidad de que su extensión haya sido más al sur de Concepción, pero es difícil comprobarlo con los documentos disponibles.

\section{El mayor tsunami registrado en la secuencia histórica de Chile colonial}

Además de reconstruir y reconsiderar el tamaño del tsunami (o de los tsunamis) en base a la documentación conocida, expondremos los aportes de algunos documentos hallados. De acuerdo a las fuentes conocidas, la «salida del mar» de 1730 hacia el norte fue notoria al menos hasta El Callao (12 ${ }^{\circ} 2^{\prime}$ latitud sur), distante 2.300 kilómetros de Santiago. El virrey, desde la vecina Lima, reportó sin especificar la hora que

se advirtieron en esta mar la nunca vista novedad de elevarse lentamente hasta cubrir las paralelas y huestes que resguardaban sus ímpetus, retirándose con algunos pasos con la misma lentitud que duró todo aquel día y buena parte del siguiente..$^{85}$

Desafortunadamente, no conocemos referencias del tsunami en la costa intermedia entre El Callao y La Serena. En esta última ciudad, solo destruyó algunos ranchos costeros, se dijo muchos años más tarde. ${ }^{86}$ No es de extrañar que el daño no haya sido mayor, por cuanto la ciudad de La Serena se restringía por entonces a su planta original, situada sobre una terraza de 30 metros de altitud y distante dos kilómetros del mar. No tenemos noticias de su puerto Coquimbo. Lo que habría al nivel del mar, como dijo el jesuita Olivares, serían ranchos costeros.

Hacia el sur, sabemos que el tsunami entró por el río Aconcagua hasta el sector de Colmo, localizado 6 kilómetros tierra adentro: «entró el mar en la boca de Colmu, donde había plantadas viñas» ${ }^{87}$ dato no considerado

85 El virrey marqués de Castelfuerte al rey, Lima, 19 de noviembre de 1730, ANH, BVM, $304-$ C. El virrey del Perú al gobernador de Chile, El Callao, 22 de agosto de 1730, AGI, Chile, 145.

86 Olivares, 1873, III, 220.

87 Se trata de una heredad llamada «La boca de Colmu», propiedad de Diez de Hidalgo, de la que informa Vicuña Mackenna en 1874. Refiere este dato de un escritor llamado Joaquín Villarino, quien entrevistó en Colmo a unos ancianos octogenarios, que «dijeron ambos que habían oído hablar a su abuelo de unas casas de teja con viñas que había cerca del mar, y que un gran temblor y salida de mar habían desaparecido», lo que Villarino relaciona «indudablemente» con la salida de mar ocurrida el 8 de julio de 1730 . Vicuña, 1874, 36-37. 
hasta ahora y que, aunque no proviene de un testigo presencial, nos parece muy relevante..$^{88}$

Sesenta kilómetros al sur de Valparaíso, en la estancia Pucauquén de la orden dominica, se experimentó una «salida de mar» que mató mucho ganado mayor y menor que estaba a orillas del mismo (figura 1C). Aunque las víctimas totalizaron varios miles, se aclara que una parte de ellas había perecido previamente por una extendida sequía y que una fracción desconocida fue producto de la inundación de $1730 .{ }^{89}$ Los testigos además declararon que secó una laguna costera:

y habiendo ido a reconocer una laguna que se halla en dicha estancia, que con el pescado que del mar le entraba y las pescas que en ella se hacían mantenía la dicha religión todo el año sus ayunos como hallé que totalmente se han [im]posibilitado dichas pescas, por habérsele cerrado la boca por donde le entraba el pescado y el agua, con unos cerros de arena que ocasionó el terremoto y salida de mar, de suerte que ha quedado seca la dicha laguna. ${ }^{90}$

Hacia 1730 Concepción se localizaba en el sitio del actual Penco, en la cabecera de la somera bahía homónima (figura 1E). Estaba asentada tan cerca del mar que pocos años después de su fundación se reportaba que «casi baten sus olas en ella y suelen bañar sus calles y aun los más retirados aposentos de las casas», «mucha parte de ella sobre misma playa». ${ }^{91}$ A esto se le sumaba que la planicie estaba dividida por un arroyo por el que entraban las mareas más altas (estero Penco). Respecto al arroyo, la «Relación del lastimoso» señala un siglo después:

como el plan por donde corre sea igual al del mar, suben por él las mareas entrando muy adentro de la ciudad, y a veces por no caber en su cauce se explayan por las calles, con peligro de los edificios y siempre con susto de que creciendo los anegue. ${ }^{92}$

Esta desfavorable localización facilitó que el tsunami de 1730 devastara Concepción. El mar entró «consecutivamente» a la ciudad tanto por la playa como por el arroyo, varias veces desde la una hasta las cuatro de la madrugada, sin dejar de haber «acomentimentas» hasta la tarde.

88 Carvajal y Gorigoitía, 2015.

89 Certificación de Miguel de Salinas, 25 de noviembre de 1730, Santo Domingo, 25 de noviembre de 1730, AGI, Chile, 145.

90 Idem.

91 González de Nájera, 1889, 12.

92 «Relación del lastimoso y horrible...», Concepción, s/f., ANH, Colección Sergio Fernández Larraín, 23. 
La población fue advertida tempranamente por testigos que observaron los primeros movimientos del mar. Como ya hemos dicho antes, pescadores que tenían tendidas sus redes fueron a revisarlas inmediatamente después del primer sismo, advirtiendo el retroceso del mar. En la primera salida, el mar inundó las casas reales y la guardia, donde había armas, municiones, soldados y presos (figura 1E). A estos últimos, por estar encerrados, el agua les llegó hasta la cintura antes de ser liberados. Considerando los dos grandes tsunamis como uno solo, se reportó que el agua subió más de diez varas de alto (8 metros), que el mar penetró tres cuadras dentro de la población y que las aguas de la bahía se retiraron media legua (aproximadamente 2,8 kilómetros) antes de volver con violencia. Olivares menciona que luego del segundo sismo el mar se retiró tres veces, y «volvió con más furia con todo el peso de aquellos montes de agua», entrando por la ciudad y arruinando más de 200 casas cercanas a la playa. Sin embargo, la segunda salida fue «la más tremenda, porque avanzaron más sus olas y fue la que causó más daño». ${ }^{93}$

Se sabe que al oriente del arroyo estaban los conventos de San Francisco, San Agustín y Nuestra Señora de las Mercedes, conformando un sector bien poblado, y el barrio de Cantarranas, localizado en un área baja (figura 1E). Al occidente, la sede del gobierno, la guardia, el hospital y las cajas reales, y detrás de estos edificios, frente al mar, estaba la planchada, sala de armas y demás almacenes del rey. La plaza mayor se extendía a una cuadra del palacio de los gobernadores, y en ella se situaba la catedral, las casas del ayuntamiento, el colegio de la Compañía de Jesús, el seminario de San José, y una cuadra más arriba estaba el convento de Santo Domingo. ${ }^{94} \mathrm{La}$ «Relación del lastimoso» dice que después de cada retroceso, el mar «revolvía [volvía nuevamente, ¿refiriéndose a dos grandes salidas?] con impetuosa furia atropellándose unas con otras las olas, ganando por instantes mucha tierra». Desde los cerros, la población observaba «montañas de aguas», que entraban por las bocas de algunas calles de la parte occidental de la ciudad, y por todas las del oriente, especialmente a través del mismo arroyo, desplomando las edificaciones. El agua se llevó los puentes que cruzaban el arroyo, y también algunas casas de madera, que las «traspuso enteras llevándolas boyando a partes bien distantes». En ambas bandas del estero cayeron «todas» las casas «hasta la de Bello, la de

93 Olivares, 1873, II, 217-218.

94 «Relación del lastimoso y horrible...», Concepción, s/f., ANH, Colección Sergio Fernández Larraín, 23. 
doña Gabriela de la Barra y la de don Ascencio». Las casas de «más adelante» resultaron «muy maltratadas hasta la de Ovando por Cantarranas». ${ }^{95}$

El balance general es que el mar «se llevó» todas las casas de la playa y del barrio Cantarranas. De los edificios públicos cayeron «a plomo» la casa de gobierno, la aledaña guardia principal, calabozos, cuarteles de caballería e infantería, sala de armas y municiones, cajas reales, veeduría general, las casas del ayuntamiento y las cárceles públicas. Se anegó la bóveda de la pólvora. De los edificios eclesiásticos, cayó el palacio del obispo, que era el más cercano a la costa, los conventos de San Juan de Dios, San Agustín y San Francisco. En la iglesia de San Francisco el agua subió dos varas (más o menos 1,6 metros). Algunas iglesias o conventos no cayeron debido a que no los alcanzó el mar o porque «los defendía su fábrica y su situación». Del hospital, administrado por los padres de San Juan de Dios, vecino al obispado «no quedó señal de él», cayendo también su iglesia. Se perdieron también graneros, bodegas de trigos y sebos, y tiendas de mercaderes, por estar vecinos a la playa.

Finalmente, el obispo de Concepción estimó que se arruinaron dos terceras partes de la ciudad, lo que confirman testigos, habiéndose «destruido o fracasado» 192 casas. ${ }^{96}$ Solo se libraron los barrios de la Merced y el de Santo Domingo. La plaza no se inundó por estar un poco más retirada de la costa. Lo mismo ocurrió con el colegio jesuita, excepto una pared nueva de cal y ladrillo, donde el agua alcanzó una vara (80 centímetros) de altura. Se les «desbarató» (se arruinó y posteriormente anegó) toda la cerca que los separaba del «palacio» de gobierno, y las aguas anegaron su huerta. Se deduce, por lo tanto, que las propiedades de los jesuitas eran contiguas al palacio del gobernador. No alcanzó el agua al seminario de San José. El agua entró, aunque poca, a la catedral por la puerta que daba a la plaza. ${ }^{97}$

$\mathrm{Al}$ sur de Concepción, solo sabemos gracias a información posterior, de 1760, que el mar entró por la boca del río Imperial (38 46’ latitud sur). Se reporta que su «entrada era buena hasta el año 1730 que la inundación

\section{Idem.}

96 Carta del maestre de campo Manuel de Salamanca, cit. en nota 23.

97 Las fuentes más directas para conocer el tsunami de Concepción son: Carta del obispo de Concepción de Chile al rey, Concepción, de 20 de agosto de 1730, AGI, Chile, 145.- Carta del maestre de Campo Manuel de Salamanca, cit. en nota 23.- «Relación del lastimoso y horrible...», Concepción, s/f., ANH, Colección Sergio Fernández Larraín, 23.- Gazeta de México, abril de 1731, en Gacetas de México, 1949, I, 323.- Testimonios del cuaderno de cargos contra Manuel de Salamanca y su defensa, en Residencia de Gabriel Cano, gobernador, capitán general y presidente de la audiencia de Chile, por José Manso, su sucesor, Santiago, 1733, AGI, Escribanía, 942B.- «Por desórdenes en una comuna», Concepción, 25 de septiembre de 1748, ANH, Capitanía General, 994. 
del mar padecida en estas costas dejó un bajo de arena en la punta norte de la boca del río». ${ }^{98}$ Del puerto fluvial de Valdivia, ubicado 850 kilómetros al sur de Santiago y único poblado costero ocupado por españoles entre Concepción y Carelmapu, sabemos que sufrió «ruina» por el sismo y que, junto con Concepción, «por la vecindad y cercanía al mar padecieron también su inundación».9 ${ }^{99}$ Sin embargo, no hemos encontrado otras fuentes locales que ratifiquen estos hechos. Mucho más tarde, a fines del siglo XIX, un historiador, sin citar la fuente, afirmó que «en Valdivia la conmoción del mar hizo subir las aguas del río, pero la inundación, que causó algunos daños, no alcanzó a ofender las fortificaciones de la plaza». ${ }^{100}$ Desde Valdivia hacia el sur hasta Chiloé no había territorio poblado por españoles, ni poblaciones costeras reconocibles, sino hasta Chiloé, provincia insular de la que no hemos hallado reportes que mencionen sus efectos en esas costas.

Fuera del reino de Chile, además de alcanzar al Callao, contamos con datos que nos permiten afirmar que el tsunami de 1730 cruzó el océano Pacífico, llegando hasta las costas de Japón. En la península de Oshika, al noreste de Honshu, inundó cultivos y campos de arroz. ${ }^{101}$

En síntesis, hemos aportado el dato de la entrada de mar por el río Aconcagua por 6 kilómetros tierra adentro. Aunque no es una información dada por un testigo presencial, nos parece relevante en el intento de caracterizar mejor el evento de 1730. Además, con la revisión de documentos conocidos, es posible relevar que el tsunami alcanzó, por el sur, no solo hasta Concepción sino a lo menos hasta Valdivia, que está 3.000 kilómetros distante del Callao.

\section{El tsunami o «salida de mar» de 1730 en Valparaíso}

Valparaíso, por entonces reducido al sector que hoy se llama El Puerto, comprendía la playa, que llegaba casi a los pies de los cerros; una estrecha calle informal que seguía sinuosa ese pie, donde había algunas construcciones, especialmente bodegas; y alguna edificación en la primera terraza de los cerros frente a la bahía (como el castillo del gobernador).

98 Amat y Junient, [1760] 1927, n. ${ }^{\circ}$ 57, 420.

99 Informe del obispo de Santiago, 1731, en Gay, 2, 1852, 484.

100 Barros, 1886, 71.

101 Soloviev y Go, 1984. 
El sector del Almendral, territorio plano y costero hoy incorporado a la ciudad, no era en 1730 un lugar habitado. La madrugada del 8 de julio de 1730 el mar inundó la todo el puerto de Valparaíso. La «Relación del espantoso» describe el avance de las olas como la peor experimentada hasta entonces por algún puerto en Chile. ${ }^{102}$ Dos semanas después, el gobernador de Chile reportó que Valparaíso se había arruinado completamente porque, además de los efectos del terremoto, el tsunami destruyó la mayoría de sus bodegas. ${ }^{103}$ La relación jesuita detalla que el mar subió ocho y media varas (siete metros) «del natural asiento en que le encierran sus playas», inundando la mayor parte del puerto, y arrastró en su retirada las casas y bodegas. ${ }^{104}$ Explicaba el jesuita Olivares, pocos años después de los hechos, que la Compañía de Jesús tenía bodegas cerca de la playa, pero «agua y terremoto las echaron por tierra». ${ }^{105}$

La mayoría de las bodegas pertenecían a comerciantes de Santiago. Almacenaban productos mientras esperaban ser embarcados al Perú, especialmente trigo. Sabemos que «las más» fueron arruinadas por el mar, siendo la mayor pérdida de Valparaíso, pues el puerto tenía solo unas pocas y sencillas casas-habitaciones en la parte baja (figura 1D). Las bodegas se localizaban paralelas a la playa, inmediatamente bajo el cerro Castillo, en la única calle ya citada. Un nuevo testimonio, fruto de esta investigación, consigna que «eran de adobe y teja fábrica, lindaban con la playa y quedaron totalmente inundadas». ${ }^{106} \mathrm{La}$ pérdida de mercancías fue total. $\mathrm{La}$ Gazeta de México de abril de 1731 informó, sin referir su fuente, que en Valparaíso «el mar, saliendo de sus términos, anegó a Flurosino [sic], y pasando por zima de las bodegas se llevó más de ochenta mil fanegas de grano», ${ }^{107}$ equivalentes a 3,5 toneladas actuales. Cargamentos de sebo también fueron dañados por el tsunami, como los 38 zurrones alcanzados por el agua, que aun después de cuatro años seguían pudriéndose sin que nadie los reclamara debido a la pérdida de la documentación durante la

102 «Relación del espantoso...», en Valenzuela, 2012, 208.

103 El gobernador de Chile al virrey del Perú, Santiago, 20 de julio de 1730, ANH, BVM, 340-C.

104 «Relación del espantoso...», en Valenzuela, 2012, 208.

105 Olivares, 1873, III, 462.

106 Sesión de un título de propiedad, entre Nicolás de Olivos y Cristóbal Rodríguez, Valparaíso, 2 de septiembre de 1730, ANH, Notarios de Valparaíso, 9. Escritura de compromiso, Manuel Fernández, fray Baltasar del Caso e Ignacio Sánchez, Valparaíso, 26 de agosto de 1735, ANH, Notarios de Valparaíso, 10. Venta de Joseph de Alemán a Isabel Valdivia de un sitio, Valparaíso, 25 de agosto de 1734, ANH, Notarios de Valparaíso, 10.

107 Gazeta de México, abril de 1731, en Gacetas de México, 1949, I, 323. 
inundación, ${ }^{108}$ como dice un documento que no había sido considerado. Como resultado, en octubre de 1730 ante el cabildo de Lima, se informó que faltó el sebo y se encareció. ${ }^{109}$ Además de esta pérdida, escasearon los almacenes disponibles para las nuevas transacciones: «en Valparaíso que no había granero ni bodega para recoger las especies que se remitían a Lima». ${ }^{110}$ Conociendo, por lo tanto, lo que era Valparaíso por entonces, debió inundarse completamente en 1730.

En cambio, en la extensa planicie arenosa del Almendral, localizada inmediatamente al sureste del puerto, el mar pudo penetrar mucho más (figura 1D). Hacia 1730 el Almendral era un sector extramuros, poco poblado y que solo tenía la iglesia y convento de la orden de la Merced como únicos edificios de importancia. El emplazamiento original de estas construcciones mercedarias, a 800 metros de la costa actual, se ha mantenido hasta hoy. El sismo dejó al convento «sumamente arruinado en sus edificios y totalmente sin iglesia». ${ }^{111}$ Un nuevo hallazgo documental de 1731 reporta que «sin duda el convento estaba hacia el mar y la iglesia hacia el oriente porque entonces seguro fue el milagro de llegar [el agua] a las puertas de la iglesia donde dejó las espumas y retrocedió». En cambio, el mar arrasó con el convento, llevándose sus papeles y documentos. ${ }^{112}$

De este modo, es probable que el tsunami de 1730 inundara el sector Almendral hasta al menos 800 metros hacia dentro de la actual línea de la costa. Y lo hizo en todo el frente de la bahía, entre el puerto por el oeste y el cerro Barón por el este (figura 1D), porque un nuevo documento encontrado indica que una bodega situada en la «punta del Morro» (actual sector y cerro Barón) fue inundada. ${ }^{113}$ Ello indica que se cubrió de agua tanto al

108 Solicitud de Francisco Pérez Pastor, administrador de bodegas, a José Basilio de Rojas y Fuentes, juez visitador de bodegas, para hacer reconocimiento de unos zurrones de sebo en descomposición que están en sus bodegas y el permiso para su expulsión, Valparaíso, 1734, ANH, Capitanía General, 592.

109 Acta del cabildo de Lima, 11 de octubre de 1730, Archivo Municipal de Lima, Libro de Cabildo, 35 .

110 Acta del cabildo de Santiago, 22 de agosto de 1730, ACS, 68-70.

111 Capítulo Provincial de 1733, APOM.

112 Libro $^{\circ}$ de estado de Convento, censos y Capellanía del Convento del Almendral de Valparaíso, 1731, APOM, Fondo Histórico, Ms. 1248.

113 No hay más información en este documento de 1736, solo de estar situada «en la punta del Morro que llaman» y que «sirve de echar trigo». Eran «casas y bodegas [que] están cubiertas de adobe y tejas». Se dice también que con el temblor y salida de mar «se perdieron todos los papeles» donde constaban, entre otras cosas, el charqui y vino recibidos. Testamento del capitán Juan José de los Reyes, Valparaíso, 28 de abril de 1736, ANH, Notarios de Valparaíso, 10. Visitas a bodegas de Valparaíso, 28 de febrero de 1726, ANH, Capitanía General, 593. Es deducible que los papeles se guardaban en la bodega, como era usual. 
oriente (el Almendral) como al occidente (el Barón) del estero de Las Delicias (actual avenida Argentina). Esta inundación entre punta y punta de Valparaíso, de 800 metros de profundidad y 9 metros de altura, ${ }^{114}$ es muy relevante si consideramos que ese sector del Almendral está hoy completamente poblado, que es el actual centro comercial de Valparaíso y lugar en que se asienta el Congreso Nacional.

\section{Conclusiones}

La recopilación y relectura minuciosa de los documentos escritos por testigos del terremoto que han sido conocidos hasta ahora por los investigadores, y la aportación de nuevos datos contenidos en documentos no considerados con anterioridad, nos han permitido caracterizar mejor el evento estudiado. En primer lugar, el terremoto ocurrido la madrugada del sábado 8 de julio de 1730 fue, en realidad, una secuencia de dos movimientos. Aunque eso es evidente en la documentación, estamos en condiciones de afirmar que ambos movimientos liberaron tal cantidad de energía que originaron cada uno una salida de mar independiente, y que no solo lo hizo el segundo, como hasta ahora se pensaba. Eso sí, solo en Concepción podemos asegurar que hubo dos tsunamis independientes. Tan recio fue el segundo que, tanto en Concepción como en Santiago se escribió que no era posible mantenerse en pie mientras duró. Su composición de varios sismos altamente destructivos sucesivos lo acerca al de 1960 en el sur de Chile.

En segundo lugar, el terremoto devastó una gran extensión geográfica, al menos 1.200 kilómetros de norte a sur y 350 kilómetros de oeste a este, cordillera de los Andes de por medio (figuras 1A y B). Al reafirmar la destrucción en el área de Copiapó y en el sur de ella mediante el testimonio del obispo Bravo de Rivero, se agregan 200 kilómetros latitudinales, porque hasta ahora se suponía que el límite del daño estaba en La Serena. Asimismo, la contextualización acerca de las zonas pobladas y despobladas del territorio de la Audiencia de Chile y de los lugares donde podría haber infraestructura pública o religiosa importante, permite comprender mejor porqué no hubo más reporte de los daños en las zonas intermedias entre Copiapó y Valdivia, y al norte y al sur de estas, y permite a la vez suponer que el movimiento fue fuerte aun más allá de ellas.

114 Carvajal y Gorigoitía, 2015. 
En tercer lugar, el tsunami fue reportado en la costa sudamericana entre El Callao y Valdivia, inundando las ciudades intermedias de Valparaíso y Concepción. De norte a sur consta que, en alguna medida (destruyendo «ranchos»), inundó el bordemar de La Serena, penetró 6 kilómetros por el río Aconcagua, en Pucauquén entró el mar y secó una laguna, inundó Concepción, tapó la desembocadura del río Imperial y, por último, penetró por el río y ciudad de Valdivia y causó daños, pero no «ofendió» a los fuertes que defendían la entrada por el río. El tsunami atravesó el Pacífico e inundó campos de arroz en Japón. No hay antecedentes de otros tsunamis conocidos de Chile colonial que hayan tenido ese nivel de proyección.

Por último, el tsunami en Valparaíso, además de inundar la estrecha playa del puerto y llegar hasta el límite de los cerros, lo hizo también en el sector del Almendral, por entonces un pago no incorporado al puerto. El mar penetró por todo el Almendral, a uno y otro lado del estero de las Delicias, desde la punta del Barón hasta el puerto, avanzando 800 metros de fondo y hasta una altura de 8 metros.

El tamaño del terremoto de 1730 fue tan singular que incluso sus contemporáneos lo diferenciaron de los anteriores, señalándolo como «terremoto magno» y caracterizándolo como el más grande sentido en el reino de Chile desde que se tenga memoria. Hoy estos antecedentes y argumentos contribuyen a proponer no solo que el terremoto de 1730 fue el mayor experimentado en Chile colonial y el mayor registrado en Chile central, sino que es posible que se acerque a la categoría de gigante (igual o mayor que $9 \mathrm{Mw}$ ). Siendo el mayor de los grandes, o gigante, es igualmente importante prestarle atención porque, atendiendo al principio geológico citado al comienzo (lo que ha sucedido en la naturaleza una vez, volverá a suceder), pone en riesgo de grave inundación la costa más poblada de Chile.

Recibido el 12 de enero de 2015 Segunda versión el 15 de marzo de 2016 Aceptado el 29 de marzo de 2016

\section{Referencias bibliográficas}

Ager, Derek V., The Nature of the Stratigraphical Record, Chichester, NY, John Wiley \& Sons, 1993.

Álvarez Ponce, Víctor Emilio, El mar y las políticas preventivas en el Perú virreinal: impacto, control y vulnerabilidad ante los tsunamis (1647-1751), Tesis 
de Maestría, Pontificia Universidad Católica del Perú, Lima, 2014, http://tesis.pucp.edu.pe/repositorio/handle/123456789/5456

Altez, Rogelio, Si la naturaleza se opone... Terremotos, historia y sociedad en Venezuela, Caracas, Editorial Alfa, 2010.

Amat y Junient, Manuel, «Historia geographica e hidrográfica con el derrotero general correlativo al plan del reino de Chile que remite a Nuestro Monarca el Señor Don Carlos III» [1760], Revista Chilena de Historia y Geografía, Santiago, 1924-1928, núms. 53 al 62.

Barrientos, Sergio, Earthquakes in Chile, en Moreno, Teresa y Gibbons, Wes (eds.), Geology of Chile, London, The Geological Society, 2007, 263-287.

Barros Arana, Diego, Historia General de Chile, Santiago, Rafael Jover Editor, 1884-1902, 16 vols.

Bengoa, José, Historia de los antiguos mapuches del sur: desde ante de la llegada de los españoles hasta las paces de Quilín: siglos XVI y XVII, Santiago, Catalonia, 2008.

Carvajal, Matías y Gorigoitía, Nicolás, «Size of the unusual 1730 central Chile earthquake, constrained by written records and tsunami deposits», en Actas del XIV Congreso Geológico Chileno, La Serena, Colegio de Geólogos de Chile, 2015, vol. 1, 344-347.

Carvallo y Goyeneche, Vicente, «Descripción histórica-geográfica del reino de Chile» [1796], 2, en Colección de Historiadores de Chile y de Documentos relativos a la Historia Nacional, 9, Santiago, Imprenta del Ferrocarril, 1875.

Cisternas, Marco, «Suelos enterrados revelan la prehistoria sísmica del centro-sur de Chile durante los últimos dos milenios», Revista de Geografía Norte Grande, 33, Santiago, 2005, 19-31.

- «El terremoto de 1647 de Chile central como un evento interplaca: ¿otra amenaza para Chile metropolitano?», Revista de Geografía Norte Grande, 53, Santiago, 2012, 23-33.

Cisternas, Marco et al., «Predecessors of the Giant 1960 Chile Earthquake», Nature, 437, 2005, 404-407.

Cisternas, Marco; Torrejón, Fernando y Gorigoitía, Nicolás, «Amending and complicating Chile's seismic catalog with the Santiago earthquake of 7 August 1580», Journal of South American Earth Sciences, 33, 2012, 102-109.

Coenen, Beltrán, Convento de San Francisco de La Serena, Santiago, Publicaciones del Archivo Franciscano, 1995.

Comte, Diana et al., «The 1985 Central Chile Earthquake: A Repeat of Previous Great Earthquakes in the Region?», Science, 233, 1986, 449-453.

Enrich, Francisco, Historia de la Compañía de Jesús en Chile, II, Barcelona, Imprenta de Francisco Rosal, 1891.

Firbas, Paul, «"En el reino que piélago es de tierra”: el terremoto de Concepción de 1730 en Lima fundada de Pedro de Peralta Barnuevo», Anales de Literatura Chilena, 12, Santiago, 2009, 13-38. 
Gacetas de México, México, Secretaría de Educación Pública, 1949 (vol. I), 1950 (vol. II).

Galdames, Juan, «Aspectos geográficos de la ciudad de Copiapó», Revista Chilena de Historia y Geografía, 134, Santiago, 1966, 136-168.

García Acosta, Virginia (coord.), Historia y desastres en América Latina, vol. I, Bogotá, Red de Estudios Sociales en Prevención de Desastres en América Latina (La Red), Centro de Investigaciones y Estudios Superiores en Antropología Social (CIESAS), 1996; vol. II, Lima, La Red, CIESAS, 1997; vol. III, México, La Red, CIESAS, 2008.

García Acosta, Virginia y Suárez Reynoso, Gerardo, Los sismos en la historia de México, México, UNAM, CIESAS, Fondo de Cultura Económica, 1996 y 2001, 2 vols.

Gascón, Margarita (ed.), Vientos, terremotos, tsunamis y otras catástrofes naturales. Historia y casos latinoamericanos, Buenos Aires, Editorial Biblos, 2005.

Gascón, Margarita y Fernández, Esteban, «Terremotos y sismos en la evolución urbana de Hispanoamérica. Ejemplos coloniales y estudio de caso», Boletín $C F+S$ [en línea], 16, 2001, http://habitat.aq.upm.es/boletin/n16/aefer.html.

Gay Mouret, Claudio, Historia física y política de Chile. Documentos, París, Imprenta de E. Thunot y Cía., 1852, vol. 2.

Giesecke, Alberto y Silgado, Enrique, Terremotos en el Perú, Lima, Ediciones Rikchay Perú, 1981.

Gould, Stephen Jay, «Toward the Vindication of Punctuational Change», en Berggren, William \& Van Couvering, John (eds.), Catastrophes and Earth History. The New Uniformitarianism, Princeton, Princeton University Press, 1984, 9-34.

- Time's Arrow, Time's Cycle: Myth and Metaphor in the Discovery of Geological Time, Cambridge, Harvard University Press, 1987.

González de Nájera, Alonso, «Desengaño y reparo de la guerra en el reino de Chile», en Colección de historiadores de Chile y de documentos relativos a la historia nacional, 16, Santiago, Imprenta del Ferrocarril, 1889.

Guarda, Gabriel O.S.B., Nueva Historia de Valdivia, Santiago, Ediciones Universidad Católica de Chile, 2001.

Hutton, James, «Theory of the Earth», Transactions of the Royal Society of Edinburgh, Edimburgo, 1788, vol. 1, 2. ${ }^{\mathrm{a}}$ parte.

Kanamori, Hiroo, «Magnitude scale and quantification of earthquakes», Tectonophysics, 93 (3-4), 1983, 185-199.

Kelleher, John A., «Rupture Zones of Large South American Earthquakes and Some Predictions», Journal of Geophysical Research, 77, 1972, 2087-2103.

Kordic, Raissa, «El terremoto de 1730 visto por el obispo de Concepción Francisco Antonio de Escandón», Cuadernos de Historia, 10, Santiago, 1999, 209-225. 
Leyton, Felipe; Ruiz, Sergio y Sepúlveda, Sergio A., «Reevaluación del peligro sísmico probabilístico en Chile central», Andean Geology, 37 (2), Santiago, 2010, 455-472.

Lomnitz, Cinna, «Major earthquakes and tsunamis in Chile during the period 1535 to 1955», Geologische Rundschau, 59, 1970, 938-960.

— «Major earthquakes of Chile: a historical survey, 1535-1960», Seismological Research Letters, 75, 2004, 368-378.

Lorenzo S., Santiago, Origen de las ciudades chilenas. Las fundaciones del siglo XVIII, Valparaíso, Ediciones Universitarias de Valparaíso, 2013 [1982].

Montessus de Ballore, Fernando, Historia Sísmica de los Andes Meridionales, Santiago, Imprenta Cervantes, Santiago, 1912-1916, 6 vols.

Murillo Velarde, Pedro, Geographia Historica, Libro IX, De la América y de las islas adyacentes, Madrid, Imprenta de don Agustín de Gordejuela y Sierra, 1752.

Olivares, Miguel de, «Historia de la Compañía de Jesús en Chile (1596-1736)», en Colección de historiadores de Chile y de documentos relativos a la historia nacional, Santiago, Imprenta Andrés Bello, 1873.

Onetto Pavez, Mauricio, Tremblements de Terre dans le Jardin d'Eden. Désastre, Mémoire et Identité au Chili (XVI ${ }^{e}-X X I^{e}$ siècle), These de Doctorat, École des Hautes Études en Sciences Sociales (EHESS), Paris, 2013.

Palacios Roa, Alfredo, «El gran terremoto de 1730: la experiencia santiaguina frente a la catástrofe», Temas Americanistas, 22, Sevilla, 2009, 1-18.

- Sismicidad histórica de la ciudad de Concepción desde su fundación en 1550 hasta su traslado en 1751, Santiago, Servicio Nacional de Geología y Minería, 2012.

- «Antecedentes históricos de la "abogacía telúrica" desarrollada en Chile entre los siglo XVI y XIX», Historia Crítica, 54, Bogotá, 2014, 171-193.

- Entre ruinas y escombros. Los terremotos en Chile durante los siglos XVI al XIX, Valparaíso, Ediciones Universitarias de Valparaíso, 2015.

- Fuentes para la Historia Sísmica de Chile, en prensa [2016].

Pérez-Mallaína Bueno, Pablo E., «La fabricación de un mito: el terremoto de 1687 y la ruina de los cultivos de trigo en el Perú», Anuario de Estudios Americanos, LVII-1, Sevilla, 2000, 69-88.

- Retrato de una ciudad en crisis: la sociedad limeña ante el movimiento sísmico de 1746, Sevilla, Consejo Superior de Investigaciones Científicas, Pontifica Universidad Católica del Perú, 2001.

- «Las catástrofes naturales como instrumento de observación social: el caso del terremoto de Lima en 1746», Anuario de Estudios Americanos, LXII-2, Sevilla, 2005, 47-76.

Petit-Breuilh, María Eugenia, Desastres naturales y ocupación del territorio en Hispanoamérica, Huelva, Universidad de Huelva, 2004.

- Naturaleza y desastres en Hispanoamérica: la visión de los indígenas, Madrid, Editorial Sílex, 2006. 
Ramírez L., David, «Algunas estimaciones referidas al tamaño del terremoto de Valdivia de 1575», V Congreso Geológico Chileno, Santiago, 1988, t. II, 319-339.

Rojas Rabiela, Teresa; Pérez Zevallos, Juan Manuel y García Acosta, Virginia (coords.), Y volvió a temblar. Cronología de los sismos en México, de 1 pedernal a 1821, México, Centro de Investigaciones y Estudios Superiores en Antropología Social, 1987.

Seiner Lizárraga, Lizardo, Historia de los sismos en el Perú, Lima, Universidad de Lima, 2009-2012, 2 vols.

Silgado Ferro, Enrique, Terremotos destructivos en América del Sur, 1530-1894, Lima, Centro Regional de Sismología para América del Sur, 1985.

Soloviev, Sergei \& Go, Chan Nam, Catalogue of Tsunamis on the Eastern Shore of the Pacific Ocean, Canadian Translation of Fisheries and Aquatic Sciences, N. ${ }^{\circ}$ 5078, Otawa, Canada Institute for Scientific and Technical Information, National Research Council, 1984.

Udías, Agustín et al., «The Large Chilean Historical Earthquakes of 1647, 1657, 1730 and 1751 from Contemporary Documents», Bulletin of the Seismological Society of America, 102 (4), August 2012, 1639-1653.]

Urrutia de Hazbún, Rosa y Lanza, Carlos, Catástrofes en Chile, 1541-1992, Santiago, La Noria, 1993.

Valenzuela Márquez, Jaime, «Relaciones jesuitas del terremoto de 1730: Santiago, Valparaíso y Concepción», Cuadernos de Historia, 37, Santiago, 2012, 195-224 [disponible en http://www.scielo.cl/pdf/cuadhist/n37/art_07.pdf].

Vicuña Mackenna, Benjamín, Quintero: su estado y su porvenir, Valparaíso, Imprenta del Mercurio, de Tornero y Letelier, 1874.

- Historia de Valparaíso, Obras completas de Vicuña Mackenna, Santiago, Universidad de Chile, Dirección General de Prisiones, 1936.

Walker, Charles F., «La clase alta y sus altos: la arquitectura y las secuelas del terremoto de Lima de 1746», Revista Histórica, 28 (1), Lima, 2004, 45-90.

- Shaky Colonialism: The 1746 Earthquake-Tsunami in Lima, Peru, and its Long Aftermath, Durham, Duke University Press, 2008. 